\title{
Preoperative visual loss is the main cause of irreversible poor vision in children with a brain tumor
}

\section{Nitza Goldenberg-Cohen ${ }^{1,2}$ *, Miriam Ehrenberg ${ }^{2,3}$, Helen Toledano ${ }^{2,4}$, Liora Kornreich ${ }^{2,5}$, Moshe Snir $^{1,2,3}$, Iftach Yassur ${ }^{3}$, Ian J. Cohen ${ }^{2,4}$ and Shalom Michowiz ${ }^{2,6}$}

1 Pediatric Ophthalmology Unit, Schneider Children's Medical Center of Israel, Petach Tikva, Israel

2 Sackler Faculty of Medicine, Tel Aviv University, Tel Aviv, Israel

${ }^{3}$ Department of Ophthalmology, Rabin Medical Center, Petach Tikva, Israel

${ }^{4}$ Department of Oncology, Schneider Children's Medical Center of Israel, Petach Tikva, Israel

${ }^{5}$ Department of Radiology, Schneider Children's Medical Center of Israel, Petach Tikva, Israel

${ }^{6}$ Unit of Neurosurgery, Schneider, Children's Medical Center of Israel, Petach Tikva, Israel

\section{Edited by:}

Hana Leiba, Kaplan Medical Center Israel

Reviewed by:

Hana Leiba, Kaplan Medical Center, Israel

Jeffrey G. Odel, Columbia

Presbyterian Medical Center, USA

${ }^{*}$ Correspondence:

Nitza Goldenberg-Cohen, Pediatric Ophthalmology Unit, Schneider

Children's Medical Center of Israel,

Petach Tikva 49202, Israel.

e-mail:ncohen1@gmail.com
The purpose of this study was to characterize the severe postoperative irreversible visual loss induced by optic neuropathy in some children with a brain tumor. The computerized database (2003-2008) of a neuro-ophthalmology service of a major pediatric tertiary center was reviewed for all children with severe irreversible visual loss (counting fingers or less) due to brain-tumor-related optic neuropathy at their last follow-up examination. Data on age, gender, etiology, initial symptoms, and signs, visual acuity before and after surgery and at last examination, neuroimaging findings, and treatment were collected. Of 240 children, 198 were operated. Of those, 10 (5\%, 5 boys and 5 girls) met the study criteria. Data for the initial visual examination were available for eight children: one had binocular blindness (uncertain light perception, counting fingers); three had monocular blindness already at diagnosis (no light perception, counting fingers, no fixation); three had 6/60 vision in the worse eye; and one had good vision bilaterally (6/10). Four children had direct optic nerve compression, four papilledema, and three gliomas. Four children $(40 \%$; with craniopharyngioma, pineal germinoma, or posterior fossa tumor) exhibited a rapid deterioration in vision after tumor depression (one direct optic nerve compression and three increased intracranial pressure); two had monocular visual loss postoperatively; vision remained stable in four (after $\geq 5$ follow-up visits), but did not improve. This study shows that tumor-related optic neuropathy may be associated with marked visual loss inspite of successful tumor resection; in $40 \%$ of children, the deterioration occurs perioperatively. Direct compression is the main cause of visual loss, while papilledema usually resolved without visual sequelae. However, autoregulatory changes may be responsible for rapid visual loss following decompression for chronic papilledema. Clinicians need reminding about the problem of postoperative visual loss and we speculate on how it can be avoided.

Keywords: severe visual loss, tumor-related optic neuropathy, rapid perioperative visual loss, children

\section{INTRODUCTION}

There are three types of optic neuropathies caused by brain tumors: compressive, papilledematous, and infiltrative. All can lead to visual loss. The visual loss in compressive lesions is attributed to the interruption of the blood supply to the optic nerve with secondary ischemic optic atrophy (Shehu and Tunau, 2005) while papilledema may cause blockage of the axonal flow (Stark et al., 1999).

Brain tumors in children can be associated with visual loss which may depend on the location, type of tumor, and duration of the disease. Posterior fossa tumors, which account for about two-thirds of all brain tumors (Wilson, 1975; Stark et al., 1999), are often associated with obstructive hydrocephalus and prolonged papilledema. Supratentorial tumors that occupy the suprasellar area (such as craniopharyngioma) directly compress the optic nerve, but may also cause hydrocephalus and papilledema
(Wilson, 1975; Nguyen and Borruat, 2005; Gelb et al., 2008; Repka, 2010) Optic nerve gliomas invade the optic nerve tissue and impair visual functions. Long-standing tumors, mainly due to delay in diagnosis, may lead to more severe and less reversible visual loss. Delayed diagnosis is more common in children because they tend not to notice or complain of mild or unilateral reductions in visual acuity (Stark et al., 1999; Defoort-Dhellemmes et al., 2006).

The aim of the present study was to describe the visual results of children with tumor-related visual disturbances after brain surgery.

\section{MATERIALS AND METHODS}

The study was approved by the local and national Human Research Ethics Committees and was conducted in accordance with the tenets of the Declaration of Helsinki. 
We reviewed the computerized database of the Pediatric NeuroOphthalmology Clinic of Schneider Children's Medical Center of Israel, a major tertiary facility, from 2003 to 2008 for all children aged less than 16 years who sustained severe irreversible visual loss due to tumor-related optic neuropathy with a follow-up of at least 4 months following surgical resection. Severe visual loss was defined as counting fingers or less. Children with reversible visual loss (optic neuritis) and reduced vision for reasons other than isolated brain tumor-related optic nerve damage were excluded.

The following data were collected from the medical files: patient age at diagnosis and at last follow-up visit, gender, initial presentation, and symptoms of the underlying disease, date of diagnosis of the underlying disease, ophthalmological and neuroimaging findings at diagnosis, after surgery, and at final exam, cause of the optic neuropathy, treatment of the underlying disease, and ophthalmological and neuroimaging findings at follow-up. In each visit examination included best corrected visual acuity and a comprehensive Neuro-Ophthalmologic evaluation, according to patient's age and level of cooperation.

We compared the preoperative and postoperative results of the individual patients on the vision tests to determine the time of onset of the visual loss and changes in vision that occurred during the course of the disease. The clinical data were evaluated to identify possible precipitating factors.

\section{RESULTS}

During the 5-year study period, 240 children with a brain tumor attended our clinic: optic pathway glioma was diagnosed in 62, posterior fossa tumor in 117, craniopharyngioma in 30, and other types in $31 ; 198$ of them were operated. Fifteen children (15/198, $7.5 \%$ ) had severe irreversible visual loss due to optic neuropathy at the last follow-up visit. Five of them were excluded from the present analysis: one died during surgery for craniopharyngioma; one was lost to follow-up; and three, all of whom had huge chiasmal and optic nerve gliomas, were too young to complete the functional vision tests. The final study group consisted of 10 children ( $5 \%), 5$ boys and 5 girls of mean age $6.9 \pm 2.7$ years at diagnosis (range 2.5-12 years) and $11.6 \pm 5.0$ years at final examination (range 6.5-20 years). The mean duration of follow-up was $5.0 \pm 4.8$ years (range 4 months-16 years). The background characteristics of the study group are shown in Table $\mathbf{1}$.

Ophthalmological data from the initial (preoperative) evaluation were available for 8 of the 10 children. The results of the vision tests are shown in Table 2.

At diagnosis before surgery, one child had severe bilateral visual loss (counting fingers in the better eye); one had no light perception in one eye; one had no fixation and failure to follow objects in one eye; one had count finger only in one eye; three had 6/60 in the worse eye; and only one had good vision (better than 6/10) in both eyes.

Treatment of the tumor consisted of complete or partial resection and shunting procedures for hydrocephalus (Table 3 ).

In the postoperative period, four children showed rapid severe bilateral visual loss (Table 2). In the other six patients, all of whom had impaired vision at presentation, visual acuity stabilized after treatment of the tumor.

Table 1 | Background data at presentation of 10 patients with visual loss due to tumor-related optic neuropathy.

\begin{tabular}{|c|c|c|c|c|c|c|}
\hline Pt. No. & $\begin{array}{l}\text { Gender/ } \\
\text { age (year)* }\end{array}$ & $\begin{array}{l}\text { Follow-up } \\
\text { (months) }\end{array}$ & Laterality* & Tumor type & $\begin{array}{l}\text { Symptoms } \\
\text { (duration/months) }\end{array}$ & Signs \\
\hline 1 & $F / 9.1$ & $4^{+}$ & $\mathrm{B}$ & $\begin{array}{l}\text { Post. fossa } \\
\text { astrocytoma }\end{array}$ & Headache, diplopia (2 months) & Esotropia, papilledema \\
\hline 2 & $M / 6.2$ & 8 & $\mathrm{~B}$ & $\begin{array}{l}\text { Post. fossa } \\
\text { meduloblastoma }\end{array}$ & Reduced vision, ataxia (2 months) & Reduced vision, papilledema \\
\hline 3 & $\mathrm{M} / 8$ & 79 & $\mathrm{~B}$ & Pineal germinoma & $\begin{array}{l}\text { Headache, reduced vision, hearing } \\
\text { loss ( } 2 \text { months) }\end{array}$ & $\begin{array}{l}\text { Reduced vision, Abnl. EOM } \\
\text { (Parinaud), papilledema }\end{array}$ \\
\hline 4 & $\mathrm{M} / 7.1$ & 12 & $\mathrm{~B}$ & Craniopharyngioma & Diplopia, falls (0.5 months) & Reduced vision, papilledema \\
\hline 5 & $M / 5$ & 75 & $\mathrm{~B}$ & Craniopharyngioma & Headache & Reduced vision, papilledema \\
\hline 6 & $F / 5$ & 48 & B & Craniopharyngioma & Reduced vision, headache (3 months) & $\begin{array}{l}\text { Reduced vision, exotropia, optic } \\
\text { atrophy }\end{array}$ \\
\hline 7 & $F / 2.5$ & 45 & M & Craniopharyngioma & None & $\begin{array}{l}\text { Reduced vision, esotropia, } \\
\text { mono-nystagmus, papilledema }\end{array}$ \\
\hline 10 & $F / 12$ & 26 & M & Optic nerve glioma & Proptosis (1 months) & $\begin{array}{l}\text { Proptosis, reduced vision, swollen } \\
\text { disk, CVO }\end{array}$ \\
\hline
\end{tabular}

Two children were totally asymptomatic at diagnosis. Seven of the eight symptomatic children had ocular symptoms already at presentation for the underlying disease. These included blurred vision ( $n=4$ ) with "bumping into objects" (in patient 3), diplopia $(n=2)$, and proptosis ( $n=2)$. The diagnosis of the tumor was made on routine examination in two patients, during neuroimaging for neurofibromatosis type 1 in one patient, and during evaluation for new-onset strabismus, noted by the parents, in one patient. CVO, central vein occlusion; EOM, extraocular movement; $M$, monocular; B, bilateral; VF, visual field. ${ }^{*}$ At presentation; ${ }^{+}$Parents refused follow-up; ${ }^{*}$ Neurofibromatosis. 


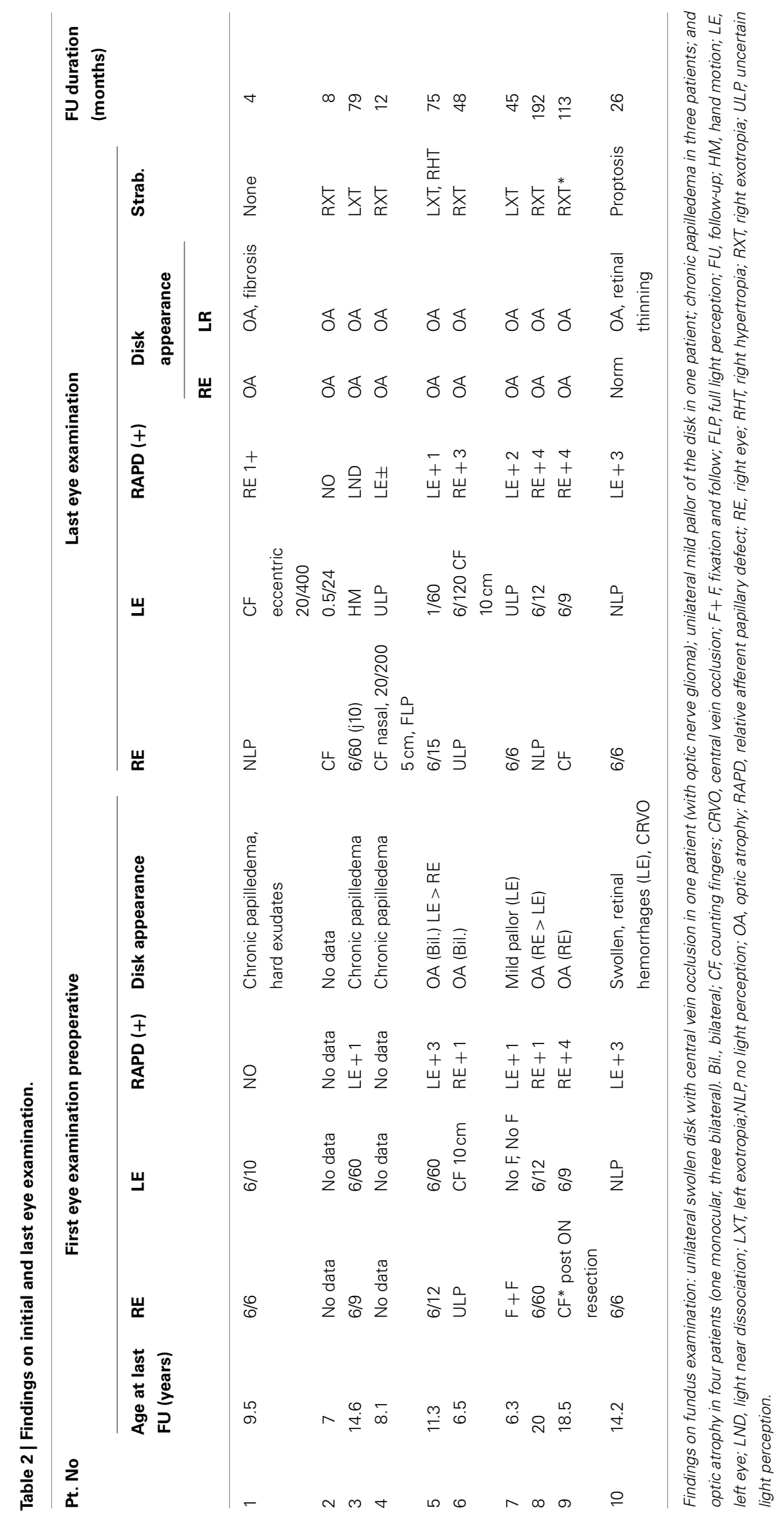


Table 3 | Treatment modalities.

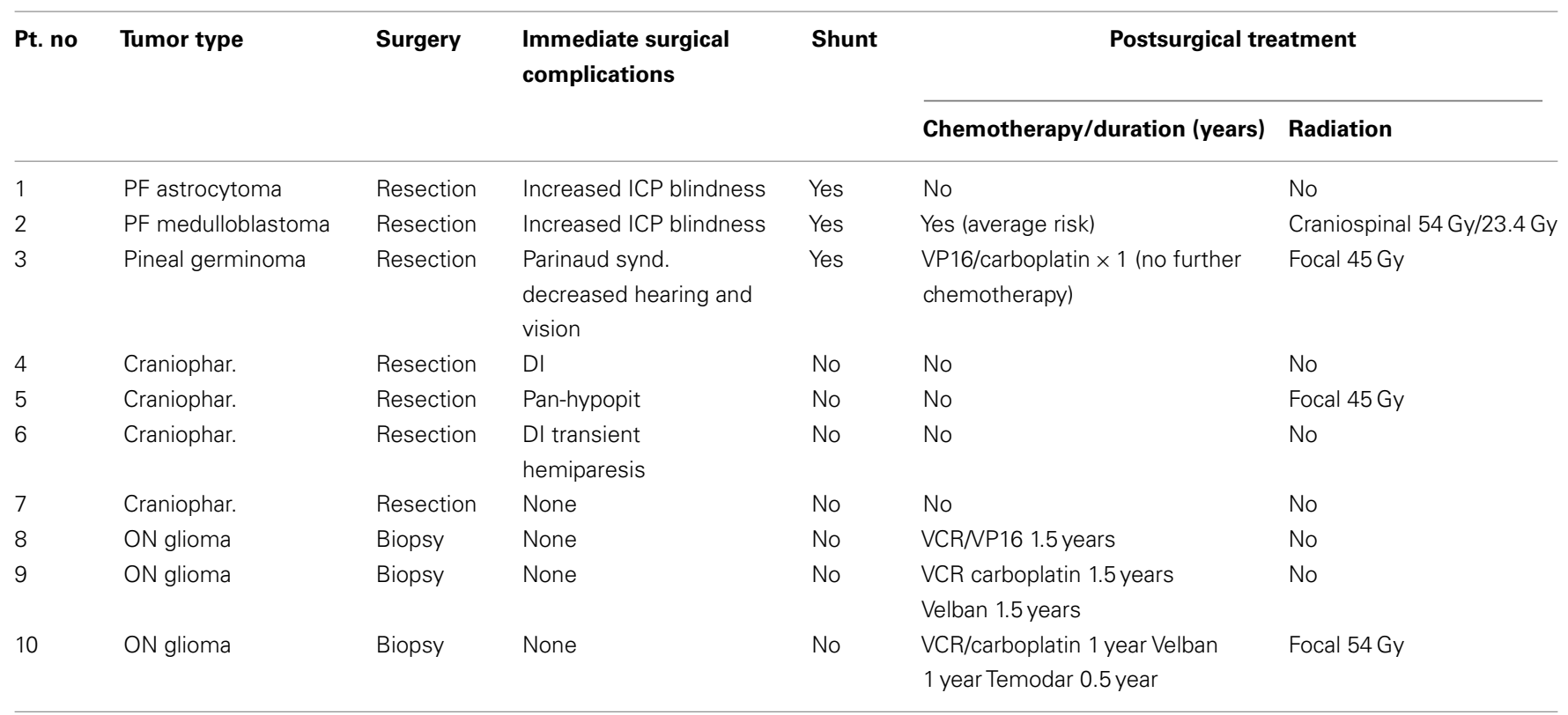

DI, diabetes insipidus; ICP, intracranial pressure; ON, optic nerve; Pan-hypopit, pan-hypopituitarism; PF, posterior fossa; VCR, vincristine; VP16, etoposide.

At the last follow-up visit, all patients had counting fingers to no light perception in at least one eye except for one patient severely constricted visual field in both eyes with acuity of 1/60. Optic atrophy was detected bilaterally in nine children and unilaterally in one.

Four children had bilateral visual loss after reduction of hydrocephalus (3/4) and tumor resection. Monocular visual loss was detected in five (three optic nerve gliomas and two craniopharyngiomas).

\section{DISCUSSION}

We describe 10 children with brain tumor that have permanent severe visual loss despite prompt treatment of the underlying tumor. Of the 10, 9 had evidence of optic neuropathy at diagnosis before surgery. In four children, vision deteriorated rapidly following tumor decompression for chronic papilledema; two of them had posterior fossa tumors. The most common tumor associated with persistent severe visual impairment was craniopharyngioma located in the suprasellar region. Delayed diagnosis and presentation with slowly progressive monocular visual loss were characteristic of hypothalamic-chiasmic glioma.

The 10 children with tumors and visual loss in the present study represented $5 \%$ of the total number of children who attended our center for treatment of brain tumors during the 5-year study period $(n=198)$. Our search of the literature yielded no reports on the incidence of rapid visual loss in children with brain tumors, either at diagnosis or during surgical and adjuvant treatment.

Tumors of the posterior fossa are the most prevalent solid brain tumors in children (Wilson, 1975; Dorner et al., 2007). Although they are associated with hydrocephalus and papilledema and delayed diagnosis, they rarely cause loss of vision (Dorner et al., 2007). This finding suggests that increased ICP, even when prolonged, is less dangerous in terms of visual loss than direct compression, such as that induced by suprasellar tumors. Nevertheless, two of the children in our cohort with posterior fossa tumors exhibited rapid postoperative visual loss and immediate pallor of the swollen disks following decompression.

Suprasellar tumors, by contrast, are associated with an $86 \%$ rate of visual loss in adults (Chakrabarti et al., 2005; Kitthaweesin and Ployprasith, 2008). In one study, one-third of patients with ocular manifestations of brain tumors had craniopharyngiomas (Kitthaweesin and Ployprasith, 2008). Reported rates of unilateral or bilateral visual loss in patients with craniopharyngioma were $3 \%$ of 68 patients (Chakrabarti et al., 2005) and $11.5 \%$ of 52 patients (Caldarelli et al., 2005). Our findings were compatible: the four children with craniopharyngioma and visual loss in the present cohort represented $13 \%$ of all children treated for craniopharyngioma at our center $(n=30)$ during the study period. The suggested mechanisms underlying the visual loss in patients with craniopharyngiomas include direct pressure, increased ICP, and papilledema.

The majority of children in this study with poor vision at the end of the follow-up had reduced vision already at diagnosis. In a study of children with craniopharyngiomas, $33 \%$ had a visual acuity of $<6 / 60$ in the better eye preoperatively (DefoortDhellemmes et al., 2006); visual signs were present at diagnosis in $96 \%$ of patients, although only one-third were symptomatic. Half the patients had loss of visual acuity at diagnosis, and about onethird had papilledema (Defoort-Dhellemmes et al., 2006). Optic nerve atrophy was detected in 38\% at diagnosis. Abrams and Repka (1997) described children with tumors affecting the anterior visual pathways, among whom $81 \%$ continued to lose vision with the development of optic atrophy. They suggested that the chronic progressive optic neuropathy was related to direct compression.

In the present study, the most impressive finding was the rapid visual loss in the perioperative period in four patients (40\%), 
of them three had papilledema and only one had direct tumor pressure on the optic nerve, suggesting that in patients with increased ICP, vision may deteriorate after rapid decompression of the tumor. The fact that some children went blind following surgery supports an association of visual loss with tumor removal. In these cases, the mechanism may involve direct trauma to the optic nerve/chiasm or its blood supply. Acute papilledema is rarely associated with vision impairment, but long-standing papilledema may cause irreversible visual loss in a minority of patients (Brew et al., 1987). Local autoregulatory vascular changes and/or diversion of the cerebral blood flow into the ophthalmic circulation may normalize blood supply to the optic nerve in the presence of increased ICP (Querfurth et al., 2002; Cremer et al., 2004), and therefore a rapid reduction in ICP could lead to immediate visual impairment due to the new autoregulatory vascular levels. As in the literature, we also suspect that the high susceptibility of the optic nerve to interruption in the blood supply contributed to the rapid visual loss (Roth and Barach, 2001; Sadda et al., 2001; Dunker et al., 2002; Lee et al., 2006; Kaeser and Borruat, 2008; Newman, 2008; Patil et al., 2008).

It is well known that early diagnosis and treatment are essential to preserve vision in tumor-related optic neuropathy, and that recovery to normal levels is unlikely if profound loss of vision continues for weeks to months (Stark et al., 1999). In children, the problem is exacerbated because they often do not verbalize unilateral visual loss (Defoort-Dhellemmes et al., 2006; Dorner et al., 2007). Accordingly, in the present study, there was a large discrepancy between the lack of visual complaints at diagnosis and the ocular findings on routine eye examination. In another study, approximately half the children were initially diagnosed and treated for other diseases (Suharwardy and Elston, 1997; Defoort-Dhellemmes et al., 2006; Dorner et al., 2007). Furthermore, given the possible association of visual deterioration with the surgery itself, as shown here, clinicians should be aware that in children, lack of awareness and poor cooperation during vision tests, may mask a rapid visual loss following tumor decompression.

This is a retrospective study, and only children with poor visual outcome were included. The small number of actual patients in the present study limits our conclusions. Brain tumors are well known as an important cause of optic neuropathy with visual loss, particularly suprasellar tumors such as craniopharyngioma and glioma. Nevertheless, the findings clearly show that in spite of successful tumor resection, children may loss vision immediately after the operation regardless of the preoperative vision, type of tumor or its location. The retrospective design of the study precluded identification of parameters predicting perioperative visual loss. Therefore, our general recommendation is to carefully monitor ICP reduction and visual function in all children with brain tumors and papilledema.

\section{ACKNOWLEDGMENTS}

This study was partly supported by the Eldor-Metzner Clinician Scientist Award, Chief Scientist, Ministry of Health, Israel (Nitza Goldenberg-Cohen, \#3-3741), and The Zanvyl and Isabelle Krieger Fund, Baltimore, MD, USA.

\section{REFERENCES}

Abrams, L. S., and Repka, M. X. (1997). Visual outcome of craniopharyngioma in children. J. Pediatr. Ophthalmol. Strabismus 34, 223-228.

Brew, B. J., Garrick, R., and Connelley, T. J. (1987). Lumboperitoneal shunting as a cause of visual loss in benign intracranial hypertension. Clin. Exp. Neurol. 23, 233-235.

Caldarelli, M., Massimi, L., Tamburrini, G., Cappa, M., and Di Rocco, C. (2005). Long-term results of the surgical treatment of craniopharyngioma: the experience at the Policlinico Gemelli, Catholic University, Rome. Childs Nerv. Syst. 21, 747-757.

Chakrabarti, I., Amar, A. P., Couldwell, W., and Weiss, M. H. (2005). Long-term neurological, visual, and endocrine outcomes following transnasal resection of craniopharyngioma. J. Neurosurg. 102, 650-657.

Cremer, O. L., van Dijk, G. W., Amelink, G. J., de Smet, A. M., Moons, K. G., and Kalkman, C. J. (2004). Cerebral hemodynamic responses to blood pressure manipulation in severely head-injured patients in the presence or absence of intracranial hypertension. Anesth. Analg. 99, 1211-1217 [table of contents].

Defoort-Dhellemmes, S., Moritz, F., Bouacha, I., and Vinchon, M. (2006). Craniopharyngioma: ophthalmological aspects at diagnosis. J. Pediatr. Endocrinol. Metab. 19(Suppl. 1), P321-P324.

Dorner, L., Fritsch, M. J., Stark, A M., and Mehdorn, H. M. (2007). Posterior fossa tumors in children: how long does it take to establish the diagnosis? Childs Nerv. Syst. 23, 887-890.

Dunker, S., Hsu, H. Y., Sebag, J., and Sadun, A. A. (2002). Perioperative risk factors for posterior ischemic optic neuropathy. J. Am. Coll. Surg. 194, 705-710.

Gelb, A. W., Craen, R. A., Rao, G. S., Reddy, K. R., Megyesi, J., Mohanty, B., Dash, H. H., Choi, K. C., and Chan, M. T. (2008). Does hyperventilation improve operating condition during supratentorial craniotomy? A multicenter randomized crossover trial. Anesth. Analg. 106, 585-594 [table of contents].
Kaeser, P. F., and Borruat, F. X. (2008) Perioperative visual loss: a rare complication of general surgery. Klin. Monatsbl. Augenheilkd. 225, 517-519.

Kitthaweesin, K., and Ployprasith, C. (2008). Ocular manifestations of suprasellar tumors. J. Med. Assoc. Thai. 91, 711-715.

Lee, L. A., Roth, S., Posner, K. L., Cheney, F. W., Caplan, R. A., Newman, N. J., and Domino, K. B. (2006). The American Society of Anesthesiologists Postoperative Visual Loss Registry: analysis of 93 spine surgery cases with postoperative visual loss. Anesthesiology 105, 652-629; quiz 867-868.

Newman, N. J. (2008). Perioperative visual loss after nonocular surgeries. Am. J. Ophthalmol. 145, 604-610.

Nguyen, C., and Borruat, F. X. (2005). Bilateral peripapillary subretinal neovessel membrane associated with chronic papilledema: report of two cases. Klin. Monatsbl. Augenheilkd. 222, 275-278.

Patil, C. G., Lad, E. M., Lad, S. P., Ho, C. and Boakye, M. (2008). Visual loss after spine surgery: a populationbased study. Spine 33, 1491-1496.
Querfurth, H. W., Lagrèze, W. D., Hedges, T. R., and Heggerick, P. A. (2002). Flow velocity and pulsatility of the ocular circulation in chronic intracranial hypertension. Acta Neurol. Scand. 105, 431-440.

Repka, M. X. (2010). The Visual System and Childhood Brain Tumor. Available at: www.childhoodbraintumor.org [accessed April, 2011].

Roth, S., and Barach, P. (2001). Postoperative visual loss: still no answers yet. Anesthesiology 95, 575-577.

Sadda, S. R., Nee, M., Miller, N. R., Biousse, V., Newman, N. J., and Kouzis, A. (2001). Clinical spectrum of posterior ischemic optic neuropathy. Am. J. Ophthalmol. 132, 743-750.

Shehu, B. B., and Tunau, K. (2005) Blindness following ventriculoperitoneal shunt block in a child with spinal dysraphism: case report. East Afr. Med. J. 82, 106-107.

Stark, K. L., Kaufman, B., Lee, B. C., Primack, J., and Tychsen, L. (1999). Visual recovery after a year of craniopharyngioma-related amaurosis: report of a nine-year-old child 
and a review of pathophysiologic mechanisms. J. AAPOS 3, 366-371.

Suharwardy, J., and Elston, J. (1997). The clinical presentation of children with tumours affecting the anterior visual pathways. Eye 11(Pt 6), 838-844.

Wilson, C. B. (1975). Diagnosis and surgical treatment of childhood brain tumors. Cancer 35(Suppl. 3), P950-P956.
Conflict of Interest Statement: The authors declare that the research was conducted in the absence of any commercial or financial relationships that could be construed as a potential conflict of interest.

Received: 20 November 2010; paper pending published: 06 February 2011; accepted: 13 September 2011; published online: 30 September 2011.
Citation: Goldenberg-Cohen N, Ehrenberg M, Toledano H, Kornreich L, Snir $M$, Yassur I, Cohen IJ and Michowiz $S$ (2011) Preoperative visual loss is the main cause of irreversible poor vision in children with a brain tumor. Front. Neur. 2:62. doi: 10.3389/fneur.2011. 00062

This article was submitted to Frontiers in Neuro-ophthalmology, a specialty of Frontiers in Neurology.
Copyright (c) 2011 Goldenberg-Cohen, Ehrenberg, Toledano, Kornreich, Snir Yassur, Cohen and Michowiz. This is an open-access article subject to a non-exclusive license between the authors and Frontiers Media SA, which permits use, distribution and reproduction in other forums, provided the original authors and source are credited and other Frontiers conditions are complied with. 